\title{
Design e sustentabilidade: a produção de novas peças de vestuário através do uso de roupas inutilizadas e resíduos têxteis
}

\author{
Glauber Soares Junior; \\ Thayenne de Moura Pereira
}

resumo:

O presente trabalho tem por objetivo apresentar os resultados do projeto intitulado "Re-construir: a produção de peças do vestuário através do uso de roupas inutilizadas e resíduos têxteis", realizado por alunos do curso Superior de Tecnologia em Design de Moda do IF Sudeste MG, no campus de Muriaé, durante os meses de março e julho do ano de 2019. Buscou-se demonstrar de forma prática, que roupas que se encontram em desuso e resíduos têxteis podem ser reutilizados através de técnicas do design. Com propósito de atingir o objetivo apresentado, nesse estudo, atribuiu-se um delineamento qualitativo, do tipo exploratório, a fim de, entender de que forma algumas empresas de Muriaé/MG e região descartam o lixo têxtil que é produzido; através disso, foram adquiridos retalhos têxteis com intuito de reaproveitá-los na elaboração de bolsas, a partir do manuseio de um tear de pregos. A coleta de informações se deu mediante a uma pesquisa bibliográfica referente à temática estudada. Enquanto resultados, destaca-se que com a realização do presente projeto, pode-se demonstrar de maneira prática que refugos têxteis e peças do vestuário que estão em desuso podem ser utilizados na produção de novos produtos, e também que a elaboração desse tipo de projeto, usando como instrumento processos criativos transformadores, contribui para a renovação do ciclo de vida de produtos, e assim, poderá gerar a conscientização dos consumidores para com eles.

palavras-chave:

Design Sustentável; Reaproveitamento; Moda; Têxtil 


\section{Introdução}

Quando se discute a temática relativa à sustentabilidade, muitos são os conceitos e de variadas disciplinas, tornando o tema interdisciplinar. No ponto de vista do design, na contemporaneidade, vem-se gradativamente no decorrer dos anos, aplicando os conceitos de Desenvolvimento Sustentável nos produtos, de acordo com as novas buscas sociais e do mercado. Nesse sentido, "[...] a análise e o design do ciclo de vida do sistema-produto são primordiais em qualquer desenvolvimento de projeto de produto ou serviço" (CAVALCANTI, et al, 2012, p. 252).

Nesse contexto que explora o papel do design na aplicação de conceitos relacionados com a temática sustentável, Silva (2014) evidencia que, na indústria da moda, no Brasil, tal área possui muita relevância para o país, no que diz respeito à questão econômica, gerando muitos postos de trabalho anualmente, contudo, é uma das que mais degradam o meio ambiente.

$\mathrm{Na}$ conjuntura cidadã, a partir dos adventos tecnológicos ocasionados pela Revolução Industrial e devido à moda estar cada vez mais democrática, fato propiciado pela difusão de movimentos culturais e sociais, a indústria têxtil passou a produzir itens em massa. Sabendo que a matéria prima básica da indústria têxtil é advinda da natureza, a produção massificada gera demasiados impactos na esfera ambiental. Sendo assim, a indústria da moda foi considerada uma das mais degradantes e poluidoras durante o século XX, e também nas primeiras décadas do século XXI, sendo os principais impactos ocasionados à contaminação de água e do ar. Dentro desse contexto, a moda produz produtos efêmeros que se tornam, muitas vezes, itens praticamente descartáveis. A manufatura têxtil está intrinsecamente atrelada à indústria da moda, conhecida por ser 'ditadora' de tendências. Esse fato, geralmente acarreta no consumo sazonal de peças de vestuário. Nessa conjuntura, "ela pode ser considerada uma das maiores degradantes de recursos naturais" (BERLIM, 2012, p. 33).

Assim sendo, os dados da Agência Brasileira de Desenvolvimento Industrial (ABID) apontam que, até o ano de 2025 há uma ampla demanda desse setor por buscar estratégias mais ecológicas e ambientais, enfatizando o aumento da produção e do consumo de insumos de forma consciente e menos agressiva ao meio ambiente, buscando, por finalidade, uma cadeia produtiva mais sustentável (ABID, 2017).

A partir do entendimento referente aos significados em relação à temática pesquisada, esse trabalho foi desenvolvido com intuito de apresentar os resultados do projeto intitulado "Re-construir: a produção de peças do vestuário através do uso de roupas inutilizadas e resíduos têxteis", realizado por alunos do curso Superior de Tecnologia em Design de Moda do IF Sudeste MG, no campus de Muriaé, durante os meses de março e julho do ano de 2019. Este projeto foi criado com o objetivo de recolocar em circulação, peças de vestuário e resíduos têxteis adquiridos na cidade de Muriaé, Minas Gerais, através de doações. Nesse contexto, novas peças foram confeccionadas a partir do material selecionado, resultando na realização de uma minicoleção de roupas e bolsas e de um ensaio fotográfico, apresentando as novas peças produzidas.

\subsection{Procedimentos metodológicos}

Com o propósito de atingir o objetivo apresentado, inicialmente, foi desenvolvido uma pesquisa bibliográfica com intuito de deter de uma perspectiva geral acerca da temática. Em um segundo momento, realizou-se um estudo de campo, com um delineamento qualitativo, do tipo exploratório, a fim de entender de que forma algumas regiões - previamente selecionadas - de Muriaé, Minas Gerais descartam o lixo têxtil que é produzido e adquirir retalhos com intuito de reaproveitá-los na elaboração de bolsas, a partir do manuseio do tear de pregos ${ }^{1}$. A escolha pelo tipo exploratório se deu pelo fato de que, conforme Gil (2008), “(...) as pesquisas exploratórias têm como principal finalidade desenvolver, esclarecer e modificar conceitos e ideias, tendo em vista a formulação de problemas mais precisos ou hipóteses pesquisáveis para estudos posteriores" (p.27). Por fim, os dados foram analisados através de uma análise de conteúdo, como proposto por Bardin (2011). Todos os processos de execução do projeto podem ser analisados através da figura 1.

\footnotetext{
${ }^{1}$ Uma configuração mais simplificada e artesanal do tear, produzido de maneira manual e concebido a partir de ripas de madeira e pregos (BAPTISTA, 2004).
} 


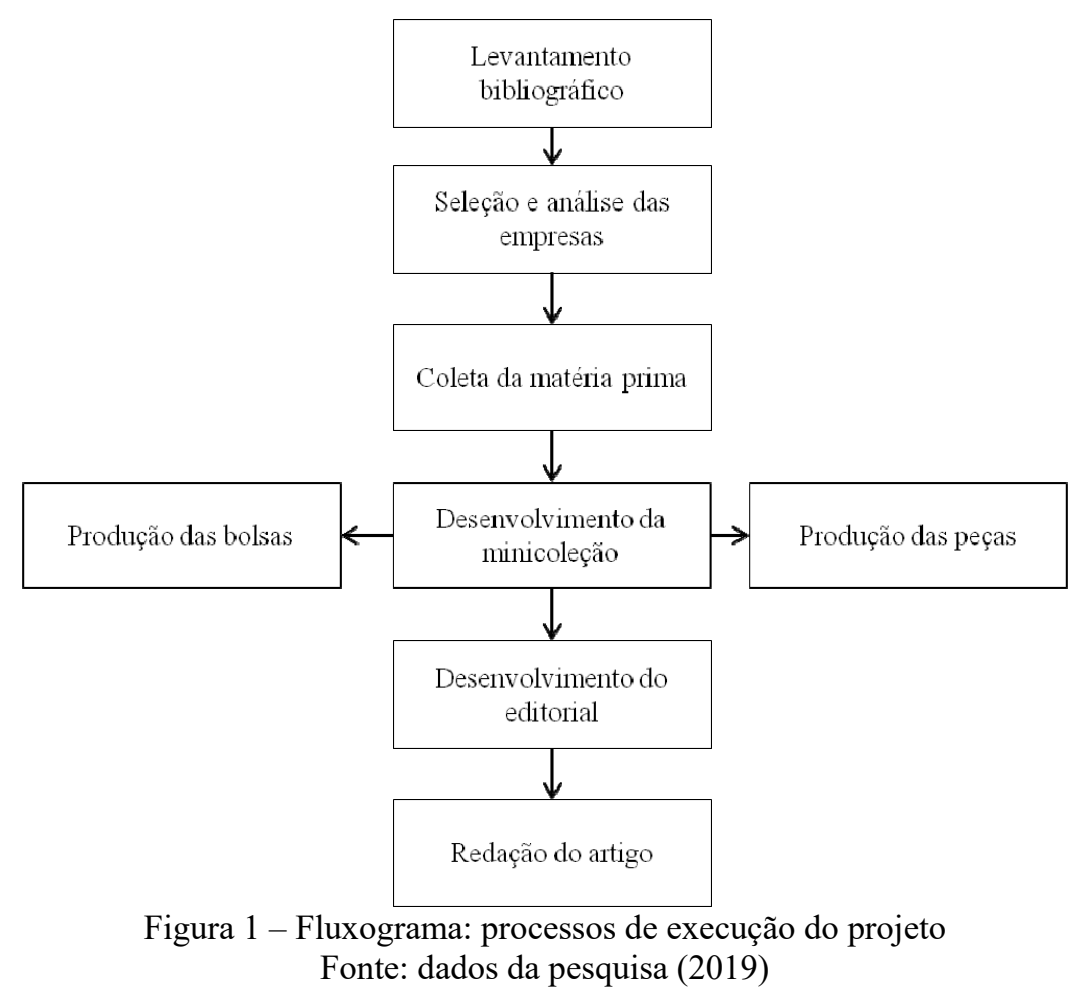

\section{Design, moda e sustentabilidade}

A sustentabilidade pode ser entendida como uma conduta que gera um cuidado com o meio ambiente, preservando a cultura e a dignidade social dos cidadãos. Nesse aspecto, o desenvolvimento sustentável, composto por três pilares, ambiental, social e econômico, evidencia-se que transformações culturais precisam ser efetivadas continuamente em prol da elevação da qualidade de vida da população e do planeta. A dimensão ambiental é importante para estimular as empresas a pensar sobre os impactos de seus serviços no meio ambiente, a fim de proteger os recursos naturais; a dimensão social baseia-se na conduta relacionada aos valores do ser humano, pois agir socialmente sustentável implica nas mudanças de atitudes, ou seja, na busca de soluções tanto no ambiente interno como externo da empresa; e a dimensão econômica consiste na produção, distribuição e consumo dos serviços, considerando as outras duas dimensões (ambiental e social), afinal esses três pilares são complementares (CARLI; VENZON, 2012).

Nessa circunstância de mudanças, o design possui um papel fundamental para o desenvolvimento sustentável, gerando novos produtos através de práticas inovativas - como a otimização do uso da água e da energia nos processos industriais; a reutilização, a reciclagem ou a restauração de roupas; e a reutilização de objetos em outros ambientes - desenvolvidas com intuito de diminuir os impactos causados ao meio ambiente e de fomentar uma mudança nos paradigmas de pensamento e comportamento, trazendo assim, benefícios para o bem estar social e ambiental (CAVALCANTO, et al 2012).

Na realização de projetos, o termo sustentabilidade foi originado do ambientalismo ${ }^{2}$, surgindo então, da evolução da conscientização acerca da preservação do meio ambiente e dos impactos socioambientais causados pelo progresso econômico, propiciado pela ampliação do consumo e da produção de objetos massificados da indústria. Nesse sentido, a utilização dos conceitos ligados à sustentabilidade em projetos de design, foi evoluindo seguindo os passos do progresso da questão ligada à esfera ambiental. O design, desde a década de 1960, vem criando alternativas que se contrapõe ao consumo exarcebado, criando projetos como o 'faça você mesmo'. O designer ao empregar o conceito de sustentabilidade promove a diminuição de impactos causados ao meio

\footnotetext{
${ }^{2}$ Movimentos sociais que possuem como preocupação essencial a preservação do meio ambiente.
} 
ambiente no decorrer da cadeia produtiva (CAVALCANTI; ARRUDA; NONATO, 2016). Os autores complementam que:

\begin{abstract}
A sustentabilidade tornou-se um princípio de referência para o estabelecimento de um novo modelo de desenvolvimento. A complexidade dos impactos ambientais e sociais, gerados pela industrialização e o excesso de consumo, exigem de diversas áreas do conhecimento e setores produtivos a constituição de pesquisas e sistemas sustentáveis, cujos resultados possam ser, de fato, materializados no cotidiano da população. [...]. O design como área intimamente relacionada ao sistema produtivo industrial e de concepção de serviços vive o desafio de desenvolver processos e sistemas mais eficientes, que possam reduzir o desperdício de recursos energéticos e materiais. Enfrentamos, por exemplo, o mau uso da energia elétrica no setor produção, de serviços e, principalmente, pelo público consumidor [...] (CAVALCANTI; ARRUDA; NONATO, 2016, p. 54).
\end{abstract}

Em um sentido mais específico do design, tratando-se do design de moda, a relação deste com a sustentabilidade é delicada. Muitas empresas que se colocam o rótulo de serem sustentáveis ganham esse status, tornando essa uma vantagem frente ao mercado. Entretanto, destaca-se que apesar do discurso, muitas dessas empresas não empregam o conceito de sustentabilidade em seus processos produtivos. Nesse sentido, a relação entre moda e sustentabilidade ainda é muito tênue, pois, são contáveis as empresas que realmente alinham o discurso sustentável com a execução (MOURA; ALMEIDA, 2013).

Apesar disso, o conceito de sustentabilidade ambiental vem ao longo dos anos se desenvolvendo em varias indústrias, não sendo diferente na da moda, mesmo que de maneira mais lenta. Tem-se evidenciado que na área da moda, todos os setores - desde a criação/design até o descarte do produto - estão absolvendo os conceitos de sustentabilidade. Nesse sentido, tem-se aumentado a preocupação com mudanças habituais, tanto dos designs quanto dos consumidores sendo uma questão intimamente ligada à outra (CALVI; FURLAN; LINKE, 2019).

Destaca-se então que, na contemporaneidade tem aumentado a procura por produtos, essencialmente os de moda, que são produzidos de maneira mais sustentável através do uso da criatividade. Nesse sentido, "estar na moda, atualmente, se tornou sinônimo de estar preocupado com as questões ambientais e sociais, com o desenvolvimento sustentável e humano dos processos oriundos deste segmento, contribuindo, cada vez mais, para uma mudança nos rumos atuais do consumo e trabalho" (JUNIOR; BATISTA; OLIVEIRA, 2019, n.p).

\title{
2.1 Moda: descarte e uso criativo de resíduos têxteis pelo design
}

É sabido que na cadeia produtiva de produtos de moda, muitos são os impactos causados por essa indústria: desde o uso exagerado de recursos naturais, até o descarte incorreto de resíduos. Nesse sentido, conforme o pensamento de Menegucci at al (2015), os materiais gerados e descartados pela indústria de confecção, recebem a configuração de resíduos.

Bortoluzzi et al (2011), apontam que os resíduos são manufaturados em praticamente todas as ocupações realizadas pelo homem. Esses resíduos são variáveis e possuem suas especificidades. Isso, de acordo com seu método produtivo e área de atuação. Nesse contexto, na atualidade, muitos setores industriais já desenvolvem ações visando à recuperação e controle sobre o impacto que essa questão gera no meio ambiente e na saúde humana.

A indústria da moda é uma das principais responsáveis pelo descarte de resíduos na natureza. São descartadas grandes quantidades de restos de tecidos, gerando sobrecarga em aterros sanitários, que já sofrem com uma superlotação de lixos que lá são descartados. Os autores elucidam que, na confecção têxtil voltada parao vestuário há uma grande produção de resíduos, mais especificadamente no setor de corte. Nesse sentido, em geral, são descartados displicentemente em aterros comuns toneladas de retalhos tendo relação direta com o acúmulo de resíduos no Brasil (Menegucci at al, 2015).

Nesse contexto, segundo Fletcher e Grose (2002), nos últimos anos, maneiras criativas estão sendo usadas para evitar ou postergar o envio de peças do vestuário aos aterros sanitários, e isso se 
deve ao surgimento do conceito do design ligado à sustentabilidade. Dessa forma, múltiplas técnicas vêm sendo desenvolvidas para renovar peças e progressivamente, estão atraindo o interesse de designers que trabalham unindo criatividade, sustentabilidade e economia. Roupas manchadas, rasgadas, e que de modo geral seriam descartadas, podem, por exemplo, servir para refazer outras roupas, apresentando um resultado singular. Peças únicas que podem ser refeitas à mão ou até mesmo com o emprego de novas tecnologias. (FLETCHER; GROSE, 2002).

Dentro dessa questão de descarte, existem três conceitos - a reutilização, a restauração e a reciclagem - que interpretam as roupas que seriam enviadas aos aterros sanitários, colocando-as de volta ao processo industrial. A reutilização é a aquisição dessas roupas para a revenda, sem fazer nenhuma intervenção. A restauração é a transformação de roupas e de tecidos desgastados em novas peças, e esse foi o conceito utilizado no desenvolvimento das bolsas e das peças do projeto aqui apresentado. E a reciclagem é a trituração das peças, onde as fibras são extraídas por processos mecânicos ou químicos. Tais autoras complementam dizendo que as vantagens da restauração de roupas são notórias e precisam do máximo de insumos para reconstrução de novas peças. Nesse aspecto, essa prática solicita muita mão de obra e se fundamenta sob uma fonte pouco convencional. (FLETCHER; GROSE, 2002).

Nesse sentido, o design, ao utilizar conceitos relativos à sustentabilidade, para além de criar produtos diferenciados, tem-se como influências positivas a diminuição de impactos no meio ambiente, melhorando a qualidade de vida da população, e isso vai ao encontro do pensamento de Menegucci et al (2015), quando dizem que:

\footnotetext{
Deste modo, a sustentabilidade tornou-se um conceito primordial para reverter o quadro de exploração excessiva de recursos naturais do planeta, já que suas práticas podem resultar em melhores condições de vida para as pessoas, melhorar a captação de recursos naturais, a reutilização de materiais descartados pelas indústrias, diminuindo a extração de novos materiais e consequentemente a degradação do meio ambiente (MENEGUCCI at al, 2015, p. 2).
}

Tendo em vista que há necessidade de renovação no clico de vida dos produtos e a conscientização dos consumidores para com eles, são utilizadas diversas técnicas com finalidade de prolongar a usabilidade. Nesse sentido, podem-se citar as técnicas de: Zero Waste (Desperício Zero), Handmade (Feito à Mão), Reciclado, e Upcycling (PINHEIRO; STEINHAUS; CHERUTTI, 2018).

Para a realização do projeto "Re-construir: a Produção de Peças do Vestuário Através do Uso de Roupas Inutilizadas e Resíduos Têxteis", as técnicas utilizadas foram: o upcling e o handmade., Nesse sentido, escolheu-se utilizar tais técnicas, pois, a técnica do handmade foi utilizada na produção da bolsas, ao serem criados novos tecidos através dos retalhos adquiridos, sendo este um processo auxiliado pela utilização de um tear de pregos. A técnica do upcling foi utilizada na produção de novas peças de vestuário, através de roupas 'velhas' que foram arrecadas através de doações. Sendo assim, evidencia-se que, através dessas técnicas, resíduos têxteis e roupas descartadas foram transformadas em novos artigos, sendo estes com valor agregado - pela produção artesanal e sustentável - podendo possuir maio valor e usabilidade.

\subsection{Sustentabilidade e design de moda: produção de novas peças de vestuário}

Em síntese, pós a consolidação das bases teóricas, o projeto foi desenvolvido em campo. Inicialmente, houve o recolhimento de material têxtil descartado por confecções de Muriaé e região - estas, previamente selecionadas; sequencialmente houve o recolhimento de peças do vestuário que não eram mais utilizadas - através de doações. Na sequência foi confeccionado um novo tecido a partir do uso do material têxtil coletado, auxiliado pela utilização de um tear de pregos e a produção de novas peças de vestuário através do uso das roupas que não eram mais utilizadas; Finalmente, houve a produção de um editorial com intuito de apresentar a pequena coleção desenvolvida. O processo pode ser averiguado com mais detalhes a seguir.

\subsubsection{Desenvolvimento das bolsas:}

No decorrer do desenvolvimento do projeto, foram recolhidos refugos de tecidos - planos, e principalmente malhas - a fim de produzir bolsas através do manuseio do tear e da utilização de 
alguns outros materiais reciclados (tais quais: caixas de leite, papelão, plásticos e papeis). As empresas selecionadas para a coleta dos tecidos foram a 'Walmisa Confecções', do distrito de Laranjal e a 'Signos Uniformes', confecção do município de Muriaé. A 'Walmisa Confecções' é uma empresa localizada na cidade de Laranjal, na região da Zona da Mata mineira. Está inserida no mercado de camisaria há 34 anos. Na empresa, foram adquiridos retalhos de tecidos planos. Já a 'Signos Uniformes' é uma empresa que possui mais de 30 anos e que comercializa linha de uniformes para todos os segmentos de acordo com a especificação de cada função e setor específico. A empresa está localizada no município de Muriaé, Minas Gerais, e, atende a todo o Brasil através de sua plataforma e-commerce. Na confecção, foram adquiridos retalhos de malhas. De acordo com os proprietários de ambas as empresas, os retalhos que as mesmas produzem não são descartados em lixões ou aterros, e sim doados ou vendidos para que possam ter outras finalidades.

Conforme fora supracitado, as bolsas foram confeccionadas através do manuseio de um tear de pregos (item confeccionado por um dos alunos do projeto), o mesmo pode ser visto na figura 2 . O tear é um aparelho mecânico ou eletromecânico usado para tecer. A sua origem é milenar e tem acompanhado o homem desde os períodos mais remotos. O tear de pregos se configura por ser uma peça de madeira com vários pregos em linha (BAPTISTA, 2004). No tear, pode ser tecida uma variedade grande de artigos, como tapetes, cachecóis, entre outros.

Os novos tecidos foram concebidos através do tear e da utilização dos retalhos. O primeiro processo foi do da separação do material. Logo após, os mesmos foram cortados em tiras de no máximo quatro $\mathrm{cm}$ de largura e entre $30 \mathrm{~cm}$ e $40 \mathrm{~cm}$ de altura. Esse processo também pode ser averiguado na figura 2. Após serem cortadas, as tiras foram entrelaçadas no tear até que se tornasse um tecido do tamanho desejado. Depois disso, as estruturas das bolsas foram produzidas através da utilização de papelão, caixas de leite e plásticos. Dentro desse contexto, após realizar a estrutura, os tecidos foram aplicados na mesma com a utilização de cola branca e cola quente. O resultado final das bolsas pode ser visto na figura 3 .

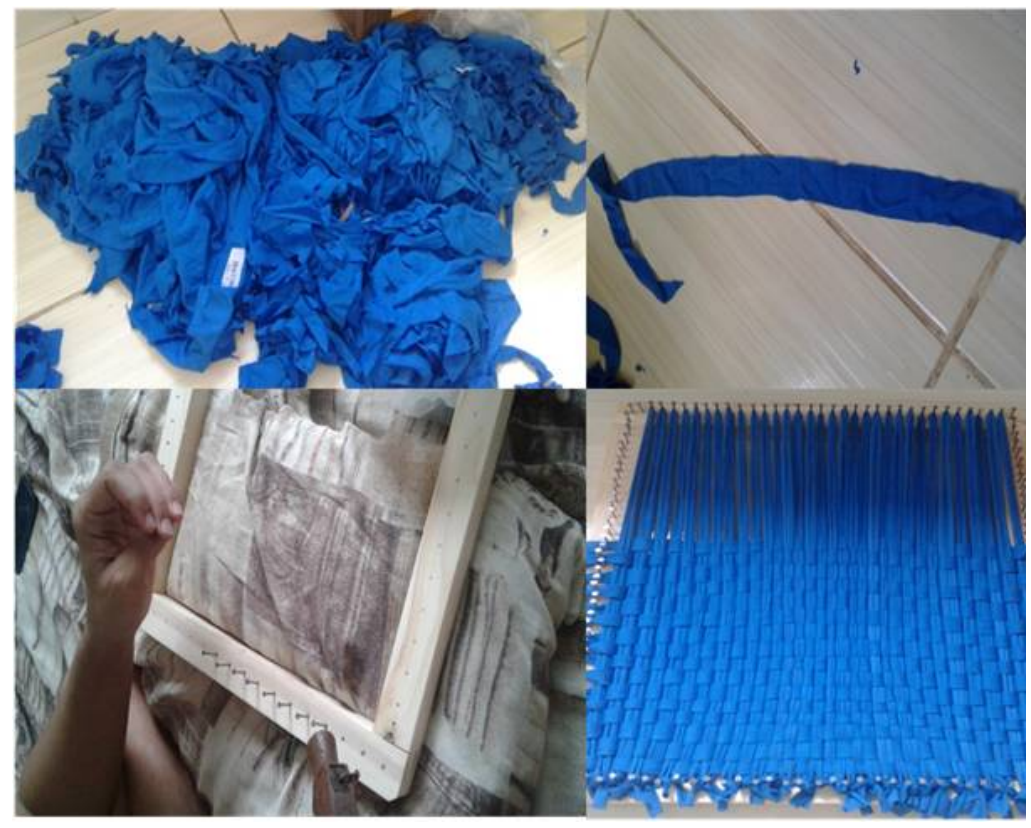

Figura 2 - Tear de pregos e retalhos Fonte: acervo dos autores 


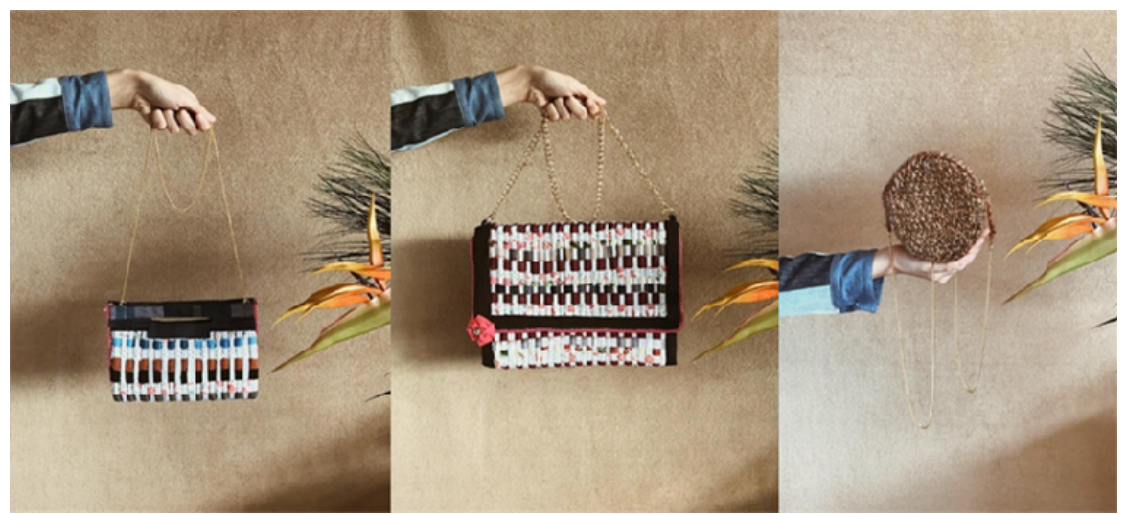

Figura 3 - Bolsas produzidas

Fonte: acervo dos autores

\subsubsection{Produção das peças e realização do editorial}

No decorrer do desenvolvimento do projeto, foram recolhidas roupas que não são mais aproveitadas, ou seja, peças mais velhas, desgastadas, e que por algum motivo não são mais utilizadas. O recolhimento se deu mediante as doações advindas dos alunos participantes do projeto. Assim, foram selecionadas, em sua maioria, roupas em jeans - uma vez que segundo Moura e Almeida (2013), este tecido apresenta um maior tempo de decomposição e por causar grandes impactos ambientais, como consumo exagerado de água em seu processo de beneficiamento, bem como pelo descarte dos efluentes gerados pelo processo em rios. O primeiro processo foi o da separação do material - calças, jaquetas e vestidos. Sequencialmente, essas roupas foram cortadas de forma que puderam ser aproveitadas todas as partes possíveis, e assim, os retalhos foram ganhando forma através da técnica do upclyning, processo auxiliado pelo manuseio de máquinas básicas para a execução da costura.

Nesse contexto de processo criativo sustentável, através de uma produção em menor escala, usando processos manuais/artesanais, e possuindo um conceito de exclusividade, torna essas produções diferenciadas, já que, a cadeia produtiva da moda é muito massificada, gerando produtos semelhantes (JUNIOR; OLIVEIRA; BATISTA, 2019).

Com todas as peças prontas, em um total de três looks - figuras 4 e 5 -, foi realizado um editorial conceitual para a apresentação das mesmas. Toda a produção foi montada pelos próprios participantes, alcançando os objetivos estabelecidos.

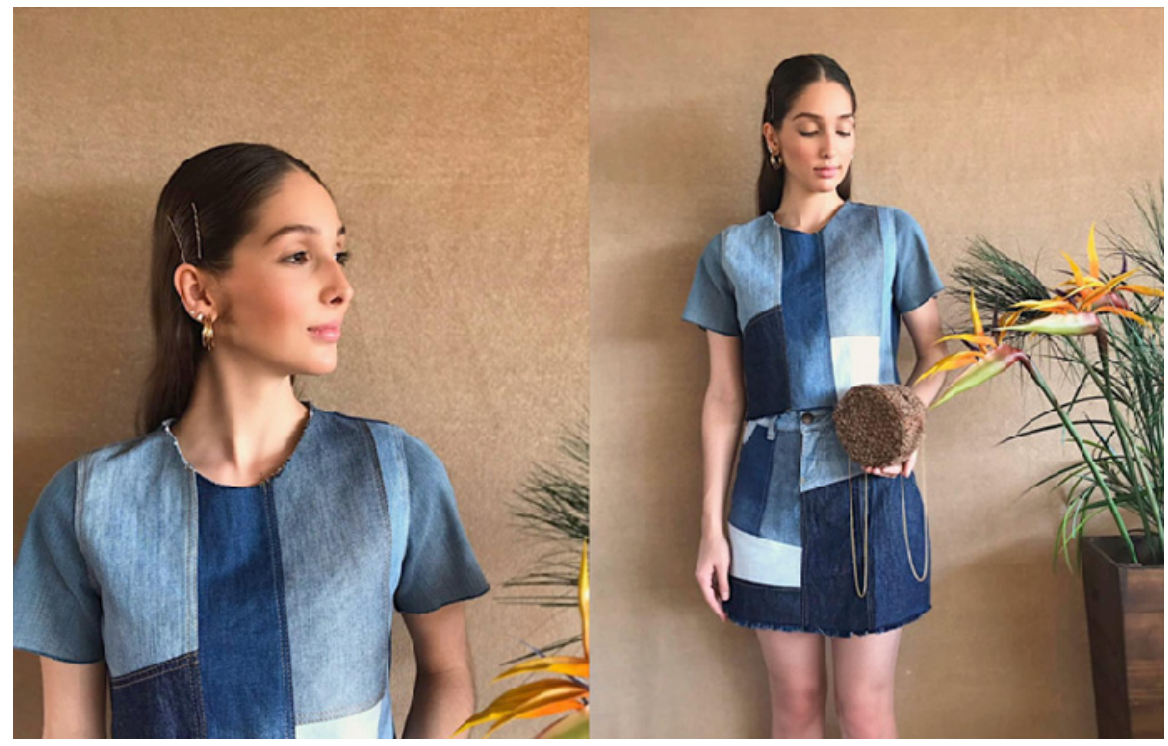

Figura 4 - Editorial: peças produzidas 01

Fonte: acervo dos autores 


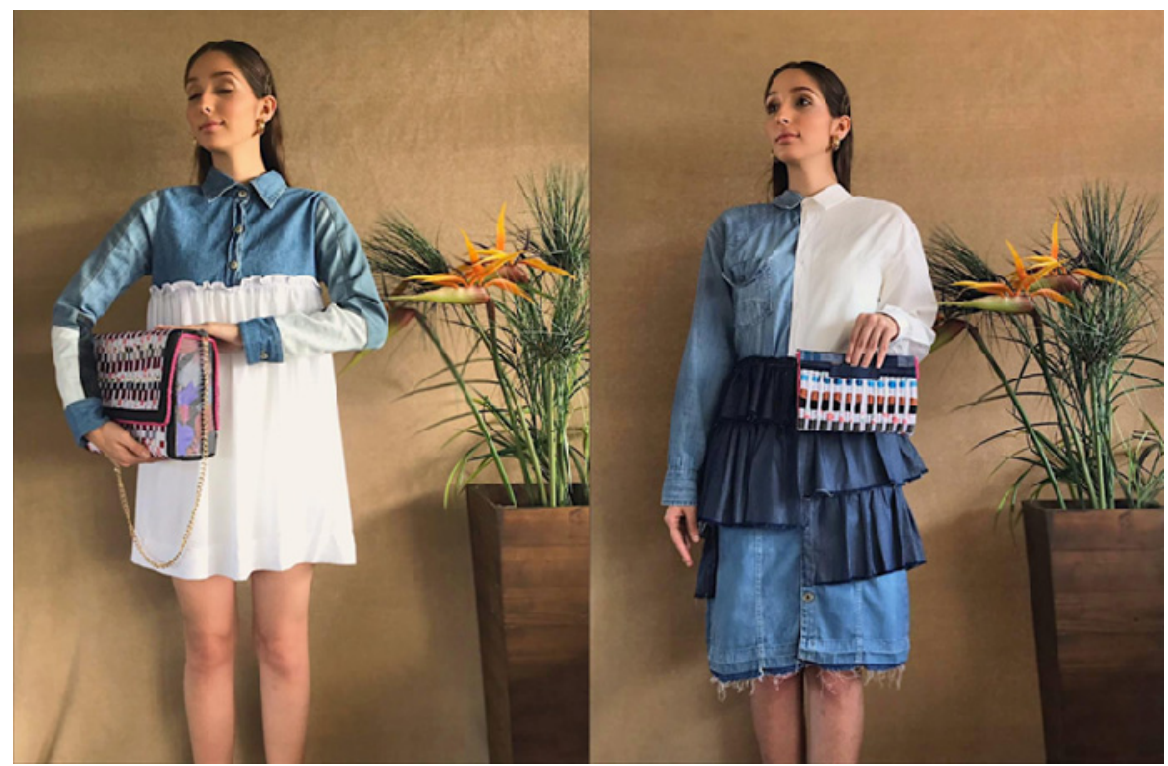

Figura 5 - Editorial: peças produzidas 02

Fonte: acervo dos autores

\section{Considerações finais}

Através do uso desenfreado de recursos naturais para a produção de artigos têxteis, vários são os problemas causados ao meio ambiente. Nessa circunstância, o design de moda precisa se ater a questões ligadas a sustentabilidade, respeitando o conceito não só no que tange ao meio ambiente, mas também ao cultural, econômico e social. Nesse sentido, mudanças como a reutilização de artigos roupas, resíduos têxteis, entre outras coisas -; a produção de produtos com uso restrito de água e energia; e o cuidado com o descarte dos resíduos que não puderem ser utilizados, são apontadas como possíveis soluções que podem acarretar na diminuição dos impactos causados nas esferas citadas. Para tal, a inovatividade e a criatividade são vistas como essenciais nesse processo de modificação (CALVI; FURLAN; LINKE, 2019).

Dentro desse contexto, com a realização do presente projeto, pode-se demonstrar de maneira prática que refugos têxteis e peças do vestuário que estão em desuso podem ser utilizados na produção de novos produtos, e também que a elaboração desse tipo de projeto, usando como instrumento processos criativos transformadores, contribui para a renovação do ciclo de vida dos produtos, e assim, poderá gerar a conscientização dos consumidores para com eles. Sendo assim, coadunando com o que foi dito por Junior, Batista e Oliveira (2019), ao se pensar em moda, atualmente precisa-se intrinsecamente pensar em sustentabilidade. Através do uso de processos criativos e conceitos do design, pode-se obter por consequência uma diminuição dos impactos causados ao meio ambiente. 
Design and sustainability: the production of new garments through the use of unused clothing and textile waste

Abstract: The present work aims to present the results of the project entitled "Re-building: the production of garments through the use of unused clothing and textile waste", carried out by students of the "Fashion Design Technology" in 'IF Sudeste MG', at the Muriaé campus, during the months of March and July of 2019. It was tried to demonstrate in a practical way, that clothes that are in disuse and textile waste can be reused through design techniques. In order to achieve the presented objective, in this study, a qualitative design was attributed, of the exploratory type, in order to understand how some companies in Muriaé/MG and region dispose of the textile waste that is produced; through this, textile wast were acquired in order to reuse them in the elaboration of bags, from the handling of a nail loom. The collection of information was done through a bibliographical research on the subject studied. As results, it is important to highlight that with the realization of this project, it is possible to demonstrate in a practical way that textile scraps and garments that are in disuse can be used in the production of new products, and also that the elaboration of this type of project, using as an instrument creative processes of transformation, contributes to the renewal of the life cycle of products, and thus, can generate the awareness of consumers towards them.

Keywords: Sustainable Design; Reuse; Fashion; Textile

\section{Referências bibliográficas}

ABID. O SETOR TÊXTIL E DE CONFECÇÃO E OS DESAFIOS DA SUSTENTABILIDADE. Brasilia: Cni, 2017. 108 p. Disponível em: https://bucket-gw-cni-static-cmssi.s3.amazonaws.com/media/filer_public/bb/6f/bb6fdd8d-8201-41ca-981d-deef4f58461f/abit.pdf. Acesso em: 27 jul. 2020.

BAPTISTA, E. H. A Imagética Rural na Estrutura do design Têxtil. Santa Maria - RS. 2004. 120 p. Disponível em: <http://repositorio.ufsm.br/handle/1/1160>. Acesso em: 03 de julho de 2020.

BOFF, Leonardo. Sustentabilidade: $O$ que é - $O$ que não é. $2^{a}$ edição. Editora

BORTOLUZZI, F. L. O. de; MORO, N. M. V; KOHL, A. Resíduos em indústrias têxteis. In: CONGRESSO INTERNACIONAL DE RESPONSABILIDADE E RECIPROCIDADE: VALORES SOCIAIS PARA UMA ECONOMIA SUSTENTÁVEL, 1, 2012, Restinga Seca. Anais [...]. [S.L.]: [S.N.], 2012. p. 532-535. Disponível em: https://reciprocidade.emnuvens.com.br/rr/article/view/74/72. Acesso em: 27 de julho de 2020.

CALVI, G. C; FURLAN, A. P; LINKE, P. P. Moda E Sustentabilidade: o que pensam futuros profissionais da área de design. Modapalavra, [S.L.], v. 12, n. 26, p. 146-170, 16 set. 2019. Universidade do Estado de Santa Catarina. http://dx.doi.org/10.5965/1982615x12262019146. Disponível em: <http://www.revistas.udesc.br/index.php/modapalavra/article/view/14317>. Acesso em: 27 jul. 2020.

CARLI, A. M. S.; VENZON, B. L. S. Moda, sustentabilidade e emergências. Caxias do Sul, RS: Editora Educs, 2012.

CAVALCANTI, A. L. B. L. et al. Design para a Sustentabilidade: um conceito interdisciplinar em construção. Projetica, [S.L.], v. 3, n. 1, p. 252, 4 set. 2012. Universidade Estadual de Londrina. http://dx.doi.org/10.5433/2236-2207.2012v3n1p252. Disponível em: <http://www.uel.br/revistas/uel/index.php/projetica/article/view/12384>. Acesso em: 27 jul. 2020.

CAVALCANTI, A. V; ARRUDA, A. O; NONATO, C. B. Sustentabilidade no século XXI: história e possibilidades de avanços através do PSS. Design \& Complexidade, [S.L.], p. 43-60, 30 dez. 2016. Editora Blucher. <http://dx.doi.org/10.5151/9788580392159-03>. Disponível em: 
https://openaccess.blucher.com.br/article-details/sustentabilidade-no-seculo-xxi-20245. Acesso em: 27 jul. 2020.

FLETCHER, K; GROSE, L. Moda e Sustentabilidade - Design para mudança. Tradução Janaína Mendonça. São Paulo: Editora Senac, 2011.

GIL, A. C. Métodos e Técnicas de Pesquisa Social. 6. ed. São Paulo: Atlas S.A., 2008. 197 p. v. 1.

JUNIOR, G. S; BATISTA, F. E. A; OLIVEIRA, I. F. POR UMA MODA MAIS SUSTENTÁVEL: O uso de pigmentos naturais no processo de beneficiamento têxtil. In: IX SIMPÓSIO DE PESQUISA E INOVAÇÃO DO IF SUDESTE MG - CAMPUS SÃO JOÃO DEL-REI - SIMPESQ, 9, 2019, São João del Rei. Anais [...]. [S.L.]: [S.N.], 2019. p. 1-2. Disponível em:

<https://cdn.even3.com.br/anais/196642.pdf>. Acesso em: 30 jul. 2020.

JUNIOR, G. S; OLIVEIRA, I. F; BATISTA, F. E. A. UTILIZAÇÃO DE PIGMENTOS NATURAIS NO PROCESSO DE BENEFICIAMENTO TÊXTIL. In: $7^{\circ}$ PASSOS PARA A MODA, 7., 2019, Passos. Anais [...]. [S.L.]: [S.N.], 2019. p. 1-10. Disponível em:

<https://passosparamoda.ifsuldeminas.edu.br/index.php/passosparamoda/7passosparaamoda/paper/ download/6/2>. Acesso em: 30 jul. 2020.

LEE, M. Eco chic: O guia de moda ética para a consumidora consciente. 10. edição. Editora Larousse, São Paulo, 2009.

MARCONI, M. A. de; LAKATOS, E. M. Fundamentos de Metodologia Científica. 5. ed. São Paulo: Atlas S.A., 2003. 310 p.

MENEGUCCI, F. et al. Resíduos têxteis: análise sobre descarte e reaproveitamento nas indústrias de confecção. In: CONGRESSO NACIONAL DE EXCELêNCIA EM GESTÃO, Não use números Romanos ou letras, use somente números Arábicos., 2015, Rio de Janeiro. Anais [...]. [S.L.]: CNEG\&OINOVARSE, 2015. p. 1-12. Disponível em: https://www.inovarse.org/filebrowser/download/8015. Acesso em: 15 de julho de 2020.

MOREIRA, R. N.; MARINHO, L. F. L.; BARBOSA, F. L. S. O Modelo de Produção Sustentável Upcycling: o Caso da Empresa TerraCycle. In: XVII ENGEMA - Encontro Internacional Sobre Gestão Empresarial e Meio Ambiente, Desafios da Sustentabilidade na Economia de Baixo Carbono, 17, 2015, São Paulo.

Anais [...]. São Paulo: FEA/USP, 2015. p. 1 - 11. Disponível em:

<http://engemausp.submissao.com.br/17/anais/arquivos/420.pdf> Acesso em: 27 de julho de 2020.

MOURA, M; ALMEIDA, M. D. de. A relação entre a sustentabilidade e o design de moda contemporâneo: uma análise sobre o segmento jeanswear. Comunicação e Sociedade, v. 24, n. 1, p. 221-251, 2013. Disponível em: <http://hdl.handle.net/11449/135342>. Acesso em: 27 de julho de 2020.

PAIVA, R. Apenas 3\% de todo o lixo produzido no Brasil é reciclado. Jornal Hoje - G1. São Paulo, abr. 2015. Disponível em: <http://g1.globo.com/jornal-hoje/noticia/2015/04/apenas-3-de-todoo-lixo-produzido-no-brasil-e-reciclado.html>. Acesso em: 20 de julho de 2020.

PINHEIRO, C. M. P.; STEINHAUS, C.; CHERUTTI, M. Um estudo sobre terminologias de sustentabilidade na moda. IARA, [S.L.], v. 10, n. 1, p. 15-28, dez. 2018. Disponível em: <http://www1.sp.senac.br/hotsites/blogs/revistaiara/wp-content/uploads/2018/12/IARA-2.pdf >. Acesso em: 06 de julho de 2020.

SILVA, C. M. S. Moda e Sustentabilidade: reuso de jeans para o desenvolvimento de produtos comerciais com valor agregado do Design. In: 2 o Contexmod - Congresso Científico Têxtil e de Moda. Anais [...]. São Paulo: [s.n.], 2014. Disponível em: <http://www.contexmod.net.br/index.php/segundo/article/view/172>. Acesso em: 27 de julho de 2020. 